14 Liu, J., Ma, H., He, Y. L., et al (2011) Mental health system in China: history, recent service reform and future challenges. World Psychiatry, 10, 210-216.

15 Schwank, S. E., Gu, C., Cao, Z., et al (2018) China's child policy shift and its impact on Shanghai and Hangzhou women's decision-making. International Journal of Womens Health, 10 639-648.
16

Phillips, M. R., Yang, G., Zhang, Y., et al (2002) Risk factors for suicide in China: a national case-control psychological autopsy study. Lancet, 360, 1728-1736.

17 Shen, Y.-C., Zhang, M.-Y., Huang, Y.-Q., et al (2006) Twelve-month prevalence, severity, and unmet need for treatment of mental disorders in metropolitan China. Psychological Medicine, 36, 257-267.

\title{
THEMATIC \\ Perinatal mental health around the PAPER world: priorities for research and service development in France
}

\author{
Anne-Laure Sutter-Dallay, ${ }^{1} \odot$ Nine M.-C. Glangeaud-Freudenthal ${ }^{2}$ and \\ Florence Gressier ${ }^{3}$
}

${ }^{1}$ Perinatal Psychiatry Network, Adult Psychiatry Department, Charles Perrens University Hospital, and Bordeaux Population Health Ce ealth Center, INSERM 1219, Bordeaux University, France. Email: alsutter@ch-perrens.fr ${ }^{2}$ CNRS-INSERM, Paris, France ${ }^{3}$ CESP-INSERM UMR1178, Department of Psychiatry, Bicêtre Bicêtre, France

Keywords. Perinatal psychiatry; France; joint care organisation.

First received 6 Nov 2019 Accepted 3 Jan 2020

\section{doi:10.1192/bji.2020.18}

(c) The Authors 2020. This is an Open Access article, distributed under the terms of the Creative Commons Attribution-

NonCommercial-NoDerivatives licence (http://creativecomm org/licenses/by-nd/4.0/), whic permits non-commercial re-use, distribution, and reproduction in any medium, provided the original work is unaltered and is properly cited. The written permission of Cambridge Universty Prission of Cambridge University Press must be obtained for com mercial re-use or in order to create a derivative work.
France has a long tradition of concern for maternal and perinatal mental health. However, the national organisation of psychiatric care does not yet provide structured guidelines on the organisation of perinatal psychiatric care. This paper provides an update on existing resources and their linkage to primary care and obstetric and paediatric services, as well as a review of current and future national priorities that are under development.

France's tradition of concern about maternal perinatal mental health began with the French psychiatrists Esquirol ${ }^{1}$ and Marcé, ${ }^{2}$ who first described maternal psychopathology emerging during the perinatal period. Their reports of the existence of specific maternal psychopathological disorders in the perinatal period should be considered in the light of changes that were occurring in French society at that time. Successive revolutionary assemblies had initially granted women some rights, including the right to divorce and to inherit on an equal footing with men. On the other hand, the violence sometimes suffered by children was also becoming recognised at this time, especially through the works of A. Tardieu, professor of forensic medicine in Paris, who first described the 'beaten child syndrome'?

In 1945, following the Second World War, a nationwide community-based mother and child protection service was established. This initiative, Protection Maternelle et Infantile (P.M.I.) was to be free of charge. It was designed to support families from pregnancy until the child's third birthday. This service provided preventive care, by means of a follow-up service for children from before birth, with regular developmental screenings and vaccinations following national guidelines. P.M.I. also provides supportive home visits by midwives and nursery nurses during the perinatal period, taking into account maternal mental health. Thereafter, the first mother-baby hospital admissions were carried out in the early $1960 \mathrm{~s},{ }^{4}$ while a group of French child psychiatrists, including Myriam David and Serge Lebovici, founded the discipline of infant psychiatry.

Other adult psychiatrists such as Thérèse Lempérière $^{5}$ have continued to build upon Marcé's work on perinatal parental psychiatric disorders. Reflecting the fact that for many years there has been a bipartite evolutionary dynamic of adult and infant psychiatry in France, the first full-time mother and baby unit (MBU), opened in Créteil in 1979, was in a child psychiatry department, whereas the second unit, which opened in 1980, was in an adult psychiatry department at the Paul-Brousse Hospital in Villejuif.

\section{Current general organisation of perinatal mental health services}

The organisation of French health services is centralised at a national level under the control of the Ministry of Health. Within this ministry, the General Health Directorate (Direction Générale de la Santé) prepares public health policy and contributes to its implementation. In addition to this work on the main areas of public health, the General Directorate of Healthcare Supply (Direction Générale de l'Offre de Soins) is in charge of the organisation of the care provided by the various health services. Regional structures (Agencies Régionales d'Hospitalisation) regulate and control the health budget at a regional level, in accordance with priorities defined at a national level. In addition to these ministerial structures, the High Authority of Health (Haute Autorité de Santé), an independent scientific public authority that aims to ensure quality in the health, social and medico-social fields for the benefit of individuals, regularly provides recommendations for good practice. 
Psychiatric treatment provided by state-employed mental health professionals is free of charge and available to everybody and is funded by the national health insurance scheme. Private psychiatric treatment is part-funded by national health insurance, but the balance may be met by private insurance. There is no limit to the number of psychiatric consultations that can be refunded by national health insurance. ${ }^{6}$ By contrast, the cost of psychotherapy provided by private psychologists is not yet refunded, except in a few special situations and for very short periods of time. The pathway to psychiatric care has no gatekeeper, and women may directly access specialised perinatal psychiatry services.

\section{Perinatal psychiatric care}

In 1970, France set up its first 'perinatal plan' to deal with relatively high rates of perinatal mortality. Another plan was drawn up in 1995 with the same objectives, and in 2005 a further plan recognised the need to integrate maternal mental health into perinatal care and established management networks that were charged with organising perinatal care at the regional level throughout France. This last perinatal plan recommended an 'early prenatal interview'. This aimed to offer all pregnant women, as early as possible during their pregnancy, an interview specifically focused on the implications of their condition, highlighting the factors that could protect or weaken their adaptation, particularly in terms of mental health.

Nevertheless, because of the orphan status of perinatal psychiatry in France, reflected in the continuing bipartite developmental lineages of child and adult psychiatry, perinatal psychiatry in France is not officially linked to either of these two subdisciplines. This in-between situation generates administrative confusion. There is no legal framework defining the field of competence of perinatal psychiatry, and that has impeded the organisation of care in this discipline. Thus, even now, it is up to individual hospitals to decide whether or not to provide access to mental health services in the context of perinatal care. Furthermore, how that care is provided will be influenced by the characteristics of the local team, depending on whether it has an adult or child psychiatry affiliation. This situation means that national coverage and access to perinatal psychiatric care in France remains very disparate.

Keeping all this information in mind, perinatal mental health services, where they do exist, are variable in structure, ranging from classical joined-up care in MBUs to hospital-based daytreatment units and out-patient psychiatric clinics. They are run by multidisciplinary teams. Depending on the locality, women and their babies can be cared for from the time of their pregnancy until 1 year after the birth, and up to 3 years in some out-patient clinics. All these structures tend to be integrated in a system of global perinatal care. This includes services in primary care settings (collaborating with P.M.I. teams, for example), as well as more specialised 'medico-psychosocial' teams, which are available to most maternity services. There are also a few perinatal psychiatry liaison teams, whose main objective is to anticipate complex psychiatric situations. The French Marcé Society maintains a list of in-patient MBUs and day hospitals providing perinatal mental health services (www. marce-francophone.fr/unites-mere-enfant-umb.html).

The type of care available to women with mental health disorders during pregnancy and in the perinatal period should be based on the severity of their illness and the biopsychosocial environmental context. ${ }^{7}$ Women with a pre-existing mental illness should be offered preconception counselling to discuss relapse risks and the potential effects of untreated illness on maternal-fetal health, as well as the risks and benefits of psychotropic medication during pregnancy and while breastfeeding. In cases of severe psychiatric illness during pregnancy or after childbirth, the mother and her infant should both be admitted to an in-patient $\mathrm{MBU}$, where the mother can receive psychiatric care while the child's safety and developmental needs and the mother-infant relationship are simultaneously supported. ${ }^{8}$ Women (and infants) admitted to MBUs have a mean length of stay of 9 weeks, and improvement rates are high $(69-82 \%$ at discharge, depending on the primary diagnosis). ${ }^{9}$ After discharge from a MBU, follow-up should entail a collaboration including the mother, her social support system and her treatment providers. It should take account of child safety. ${ }^{10}$ Women presenting with mild-tomoderate illness or with some disturbance of mother-infant bonding can be treated by outpatient perinatal psychiatry services, either in the context of private practice or by community-based ambulatory care. Guidelines for pharmacological management during pregnancy are provided by the National Agency for the Safety of Medicines and Health Products (ANSM.sante.fr) and by the Reference Centre on Teratogenic Agents (lecrat. fr). Until now, the Haute Autorité de Santé has not provided specific guidelines for managing maternal mental health during the perinatal period or recommendations about the optimal monitoring of high-risk pregnancies.

\section{Priorities}

France is probably one of the few European countries where perinatal psychiatry has been developed, even though national coverage by services has not yet been achieved. This may explain the results of a recent national cohort study (Étude Longitudinale Française depuis l'Enfance; www. elfe-france.fr). The survey found that although $12.6 \%$ of women reported experiencing psychological difficulties during pregnancy, only $27.4 \%$ of vulnerable women had access to a mental health consultation. That proportion was highest among women of low socioeconomic status; those who consumed tobacco and/or alcohol during their pregnancy, had an unplanned 
pregnancy, or were late to seek antenatal care; and multiparous women and those with obstetric complications. ${ }^{11}$ Thus, the results of the survey indicate that access to perinatal mental healthcare needs to be improved. The implementation of coordinated, graduated, integrated and, above all, systematised perinatal joined-up care programmes should be available to all women and their infants throughout the perinatal period, wherever they live in France. This is a priority that overlaps with a need for more research, the main objective of which should be to define the current care pathways available to women during the perinatal period, as well as to evaluate their relevance and their potential benefits to women's mental health and child development.

Psychiatry and, more specifically, child psychiatry and perinatal psychiatry are current priorities, according to our Ministry of Health. The President of the French Republic has convened a committee of experts to discuss the 'First 1000 Days of the Child', with five objectives. First, to come to a scientific consensus about existing theories of childcare and development, thereby providing consistent and clear key messages to parents. Second, to propose a new pathway for support to parents during the first 1000 days after birth. Third, to propose ways of detecting and treating early childhood developmental disorders. Fourth, to rethink the issue of maternal and paternal pregnancy- and birth-related leave. Fifth, to plan a revision to our early childhood care system within 10 years. There is also a plan to create a Francophone Alliance for Perinatal Mental Health modelled on and aided by the global alliance for maternal mental health (globalalliancematernalmentalhealth.org). This plan aims to bring together patient groups, midwives, and gynaecologists and obstetricians (C.N.G.O.F.), as well as associations with responsibility for maternal social care, perinatal psychology and psychiatry, including the Francophone Marcé Society, WAIHM-France. These recent initiatives highlight the positive dynamic that now exists in French perinatal psychiatry.

\section{Author contributions}

A.-L.S.-D. wrote the first draft of the manuscript. N.M.-C.G.-F. and F.G. finalised it.

\section{Declaration of interest}

None.

ICMJE forms are in the supplementary material, available online at https://doi.org/10.1192/bji.2020.18.

\section{References}

1 Esquirol E. Des maladies mentales considérées sous le rapport médical, hygiénique et médico-légal [Mental illnesses considered from a medical, hygienic and forensic perspective.] Baillières, 1838.

2 Marcé LV. Traité de la folie des femmes enceintes, des nouvelles accouchées et des nourrices [Treatise on mental disorder in pregnant, postpartum and breastfeeding women.] Baillières, 1848

3 Tardieu A. Étude médico-légale sur les sévices et mauvais traitements exercés sur des enfants. [Forensic study on the abuse and ill-treatment of children.] Annales d'Hygiène Publique et de Médecine Légale, 1860

4 Racamier PC, Sens C, Carretier L. La mère et l'enfant dans les psychoses du post-partum. [Mother and child in postpartum psychoses.] Evol Psychiatr 1961; 26: 525-707.

5 Lemperière $\mathrm{T}$, Féline $\mathrm{A}$. Les troubles mentaux liés à la gravido puerpéralité - le déni de grossesse. [Mental disorders in pregnant and puerperal women - the denial of pregnancy.] In Psychiatrie de l'adulte (eds Lemperière T, Féline A, Adès A, Hardy P, Rouillon F): 464-65. Elsevier Masson S.A.S, 2006.

6 Verdoux $\mathrm{H}$, Tignol J. Focus on psychiatry in France. $\mathrm{Br}$ ] Psychiatry 2003; 183: 466-71.

7 Sutter-Dallay AL, Glangeaud-Freudenthal NMC, Guedeney A, Riecher-Rössler A. (eds) Joint Care of Parents and Infants in Perinatal Psychiatry. Springer International, 2016.

8 Brockington I, Butterworth R, Glangeaud-Freudenthal NMC. An international position paper on mother-infant (perinatal) mental health, with guidelines for clinical practice. Arch Womens Ment Health 2017; 20(1): 113-20.

9 Glangeaud-Freudenthal NM, Sutter AL, Thieulin AC, Dagens-Lafont V, Zimmermann MA, Debourg A, et al Inpatient mother and child postpartum psychiatric care: factors associated with improvement in maternal mental health. Eur Psychiatry 2011: 26(4): 215-23.

10 Glangeaud-Freudenthal NMC, Sutter-Dallay AL, Thieulin AC, Dagens V, Zimmermann MA, Debourg A, et al Predictors of infant foster care in cases of maternal psychiatric disorders. Soc Psychiatry Psychiatr Epidemiol 2013; 48(4): 553-61.

11 Bales M, Pambrun E, Melchior M, Glangeaud-Freudenthal NM, Charles MA, Verdoux $\mathrm{H}$, et al Prenatal psychological distress and access to mental health care in the ELFE cohort. Eur Psychiatry 2015; 30(2): 322-8. 